\title{
Social-ecological priorities of town-planning activities on the urbanized territories
}

\author{
Vyacheslav Buzyrev ${ }^{1}$, Irina Nuzhina $^{2,3 *}$ and Maria Zolotareva ${ }^{2}$ \\ ${ }^{1}$ Saint Petersburg State University of Economics, Sadovaya str., 21, 191023, Saint-Petersburg, Russia \\ ${ }^{2}$ Tomsk State University of Architecture and Building, Solyanaya sg., 2, 634003, Tomsk, Russia \\ ${ }^{3}$ Tomsk State University of Control Systems and Radioelectronics, Lenina Prospect, 40, 634050, \\ Tomsk, Russia
}

\begin{abstract}
The purpose of the study is to determine the paradigm of modern urban activity development justifying the dominant influence of social and environmental factors on the modern model of urbanized areas. The methods of systemic, logical and comparative analysis are applied, as well as the results of the public opinion survey on the comfort of the urban environment, the findings of the authors' own research on identifying preferences and needs of the population in environmental construction products with an emphasis on the quality of the urban environment. The role and the content of social and ecological aspects of human vital activity environment that determines the priorities of modern development of urban development in the regions of Russia is shown. The indicators of housing construction are analyzed, the role of large-panel housing construction in solving strategic problems of housing provision based on the environment comfort is considered. The obtained results can be used to develop methods and tools for regulating construction activities.
\end{abstract}

\section{Introduction}

The main priority of Russia's strategic long-term development is to ensure a high level of life quality, inextricably linked with the creation of a safe and comfortable environment for life activity and environmental life conditions. Ecological safety is the most important element of national security of the country [1].

In the XXI century, the environment of human life is a reflection of the results of its activities, both production and household. There was a qualitatively different stage in the development of society - the "epoch of the noosphere". The founder of the noosphere theory V.I. Vernadsky considered the noosphere as the highest stage in the development of the biosphere, into which the human environment is gradually transformed governed by the activities of its scientific mind. Thus, the present and future of all mankind depends on the rationality of economic activity. Harmonization of human behavior, its needs and opportunities of preserving the biosphere in the epoch of noosphere is possible, if the human

\footnotetext{
${ }^{*}$ Corresponding author: irinanuzhina@yandex.ru
} 
economic activity is regulated. The basis for the organization of conscious regulation of human economic activity was the concept of sustainable development.

The studies have shown that the problem of finding mechanisms that ensure sustainable development of territories, including improved urban planning, remains relevant for more than a decade [2]. The development of town-planning activity in urbanized areas actualizes both, the problems of housing construction quality, and also the preservation of ecological systems, natural landscapes, historical monuments, culture and architecture [3]. It is not accidentally that at the turn of the 20th and 21 st centuries, the concept of a "town ecological frame" appeared as a reflection of the importance of the biosphere state, ecosystems for the vital activity environment of the large and largest cities in the world [4]. Today, "the problems of engineering-planning, natural-ecological and social nature" became very acute for urban agglomerations, life support systems in the city's conditions are formed under the influence of natural and man-made factors $[5,6]$.

The studies have shown that the modern presentation of the environmental consequences of urban development goes beyond the assessment of the nature of changes in the state of the atmosphere, reservoirs, soil. The space of human activity is the result of town-planning transformations and is closely interrelated not only with the change of environment-forming elements and natural-resource characteristics of the territory, but also with socio-economic, socio-psychological and socio-cultural factors of society development. The latter circumstance, in our opinion, should determine the current model of urban development in the urbanized areas. Given the full list of factors that determine the quality of the living environment, the regulatory and legal framework in construction and environmental sphere should be formed.

\section{Literature review}

The studies on the problems of urban planning regulation with the environmental aspects are interdisciplinary in nature and include research on economics and management in construction, environmental economics, ecology of urbanized areas and building ecology. The works of Plotnikova (2008), Krygina (2015), Nikolaev $(2015,2016)$ are centered around the issues of ecological support of construction activities and their importance for the formation of life environment and development of housing construction; the issues of ecological safety of construction and management are discussed in the works of Telichenko et al. (2016), Lukmanova (2014), problems of ecological safety, greening of production and ecological innovations in works Morgunov et al. (2017), Chuanqi (2012), Rudneva et al. (2016), Zakharova et al. (2015), Kasianenko et al. (2015). The problems of sustainable development of construction and architecture, environmental infrastructure development, preservation of environmental quality in conjunction with the design of urban landscapes were studied in the works of Tetior (2008), Volskaya et al. (2013). The city's life support system is regarded as a multi-component structure of natural and man-made nature in the work of V. Il'ichev et al., (2015). The social aspects of town planning were considered in the works of Grabovyy (2016). At the same time, there are insufficient studies with an applied focus on the problems of interrelation of social, economic, organizational, managerial and environmental aspects of urban planning regulation, including the mechanism of social and environmental responsibility of the construction business.

\section{Materials and methods}

Over the past ten years, the regulatory and legal framework has been actively improved in Russia, regulatory acts, government orders have been adopted, changes have been made in 
laws, a number of state programs have been developed and are being implemented in the sphere of environmental development, and the standardization system is being improved. The December meeting (2016) of the State Council was devoted to the issues of environmental development of the Russian Federation in the interests of the future generation, and 2017 was declared the Year of ecology and specially protected natural territories. Whereas, the transition to a large-scale ecologization of town-planning activities should be based on the coverage of the entire range of interrelated environmental, economic and social factors throughout the life cycle of construction products [7, 8]. However, as V. Telichenko and A. Benuzh note, at present there are no national standards in Russia reflecting an integrated approach to regulating urban development in the field of green technologies, with an account of interconnection of energy efficiency, resource saving, environmental safety and comfort of living environment. In order to conduct standardization work using "green" technologies, the scientists developed a concept proposing to create a Technical Committee for standardization "Green Technologies of life activity environment " [9].

The management system of construction organizations should also be oriented on the regulation of urban development taking into account the interrelationship of the entire range of social and environmental factors [10]. The authors share the I.G. Lukmanov's approach, proposing to form a unified management system in the management structure of the organization based on the integration of quality management systems, environmental management, health and safety management [11].

Despite the measures taken, the anthropogenic problems significantly hasn't decreased. In 44 cities (20\%), the degree of air pollution in 2015 was estimated as very high and high, in $62 \%$ of cities - low. In cities with a high and very high level of air pollution, there is 17.1 million of people, which is $17 \%$ of the urban population of Russia. Among these cities is St. Petersburg. In $59 \%$ of cities in Russia (147 cities), where the observation was made, the average values of the concentration of harmful substances exceed the threshold limit values (TLV), and in these cities there are 50.7 million people. In 34 cities, the maximum concentrations exceed the TLV by 10 times. As before, waste remains a topical issue.

In general, in the Russian Federation in 2015, the amount of accumulated and recorded production and consumption wastes in the RF as a whole was about 31.5 billion tons, of which over $57 \%$ is in the Siberian Federal District (SFD). In the total volume of waste generation, the share of the type of economic activity (TEA) "Construction" accounts for less than a percent, and about $44 \%$ are processed and reused [12]. According to Russians, the ecological situation is one of the key factors of health. It should be noted that in comparison with 2015 in 2016, the number of respondents who noted the importance of this factor for health in Russia increased from $43 \%$ to $82 \%$, and in Moscow it decreased from $79 \%$ to $66 \%$. Preservation of natural landscapes remains an urgent problem in the sphere of town planning. A significant number of lands from the productive turnover is allotted to the urban development. So, for 2015, 145.8 thousand hectares were allotted for land building. This is almost equal to the volume of withdrawal of lands for 2010-2014 - 150,7 thousand hectares. (Fig.1). In 2015, the increase in land withdrawal amounted to $2.48 \%$, which is higher than the level of all previous years. 


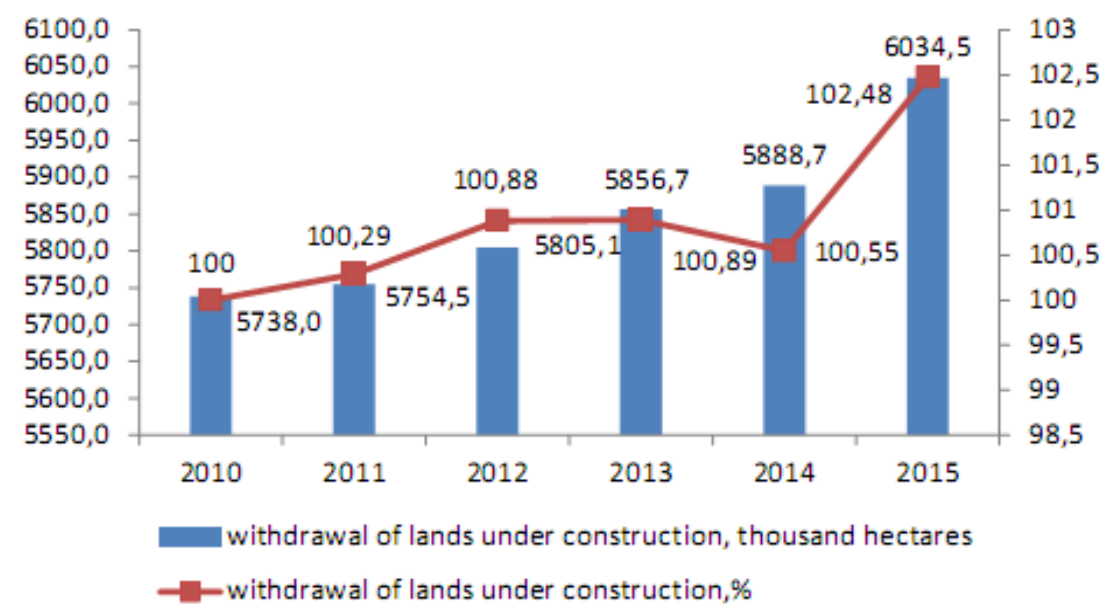

Fig. 1. Dynamics of land acquisition for construction.

Certainly, cities need new territories for development. According to a poll conducted by the All-Russia Public Opinion Research Center (2015), only 8\% of respondents prioritized the interest in resolving the issue of land withdrawal for development area, $48 \%$ - gave priority to the interests of citizens living in this territory, $37 \%$ are for environmental protection. It is important that $53 \%$ of Russians when taking a decision to purchase housing noted the ecological condition of the area as a determining factor. Only $27 \%$ of respondents support high rates of construction to solve housing problems, while $63 \%$ prefer the new construction, subject to its compliance with environmental standards, architectural and historical features of towns. According to a poll conducted by the All-Russian Public Opinion Research Center, in 2016, 23\% of respondents said that garbage, dirt, and the condition of yard spaces are among the main problems of improving towns that interfere with comfortable living; $22 \%$ pointed to lack of roads, sidewalks; $12 \%$ - lack of parking; $8 \%$ - lack of playgrounds; $6 \%$ - lack of landscaping and felling of trees; $5 \%$ - environmental pollution; 5\% - poor improvement of the town and yards [13].

Similar conclusions were obtained from the results of studies carried out by the authors during a survey of residents of one of the oldest cities in Siberia - Tomsk. Tomsk is a large educational center of Russia, rich in natural resources, has unique monuments of wooden and stone architecture. The state of the social and ecological environment of the city is formed by various factors, among the main ones, according to respondents, are the condition of the facades and the architectural look of the buildings, improvement and sanitary condition of the streets. The results of the research showed that $77.5 \%$ of respondents noted too much advertising on the town streets and buildings, which hinders the aesthetic perception of the city's architecture. Then in the decreasing order of dissatisfaction follow the sanitary condition of streets and courts (63\%), the level of improvement and gardening (57\%). 50\% of respondents were not indifferent to the architectural look of the buildings, $63 \%$ of respondents were not satisfied with the level of improvement and gardening of the adjacent territories. In general, more than half of the respondents $(57 \%)$ are not satisfied with the quality of the environment in the residential micro-districts in which they live. The research showed that $62 \%$ of respondents are ready to make a choice in favor of a more environmentally friendly but also more expensive housing, $79 \%$ of respondents prefer to choose housing built of environmentally friendly building materials. 
Thus, the current trends in studies of the preferences of the population show that an increasing number of potential homebuyers consider the habitat as a living space and the result of architectural and town-planning changes that are closely interrelated with the ecological, socio-psychological and socio-economic conditions of residential units.

The socio-ecological aspects of the territories development are relevant for a significant number of Russian regions. Figure 2 presents the results of the socio-ecological rating (green index) of the Tomsk region (TR), Leningrad region (LR), St. Petersburg ( $\mathrm{SPb}$ ) according to the NGO "Green Patrol" [14]. This rating is considered as a comprehensive indicator of the people's living comfort, with an account of regional characteristics. As can be seen from the presented data, the social and environmental index for the Tomsk region increased from 59 in 2011 to 62 in 2016, In the Leningrad Region, after a slight decrease in 2014 and 2015, the index increased to 62 in 2016. There is a positive index dynamics in St-Petersburg, by 2016 the index has increased to 70 . Figure 2 presents data for the region that is the leader by this indicator, this is the Oryol region (OR). Over the three years (2012-2014), the index was 80 -81 .

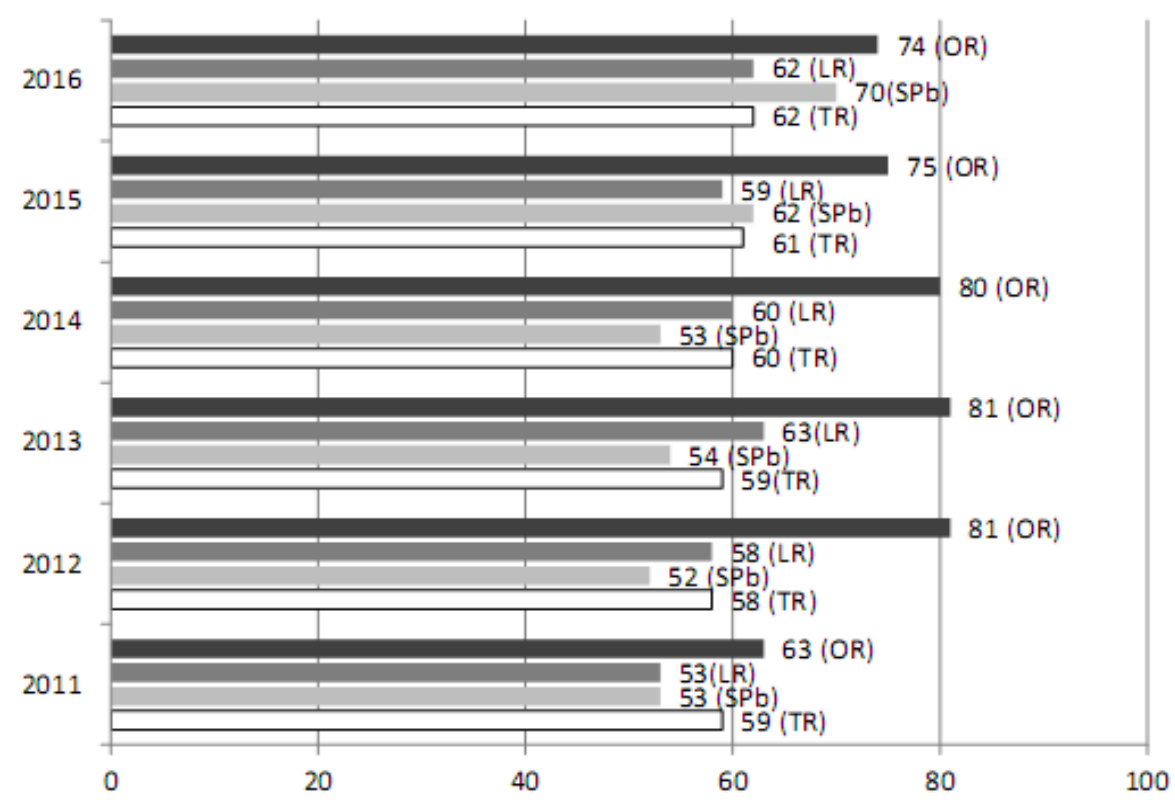

Fig. 2. Socio-environmental index of the territories for 2011-2016.

The town planning is directly related to the formation of socio-ecological ranking of the territories. The main socio-ecological benchmark for the town development is the provision of environmental comfort. It is the priority of comfort that facilitated the initiation at the national level the priority project "Building a comfortable town environment", which was launched in many regions of the Russian Federation. For the provision of the necessary amenities of Russian cities in 2017, it is planned to allocate from the federal budget 20.5 billion rubles and more than 7 billion rubles - from the budgets of the subjects of the Russian Federation.

Since 2011, the annual volume of housing construction in the Russian Federation is steadily increasing. If in 2010 the number of residential houses was 58.4 million $\mathrm{m}^{2}$, then in 2015 it was 85.3 million $\mathrm{m}^{2}$ [15]. The volume of housing construction in Russia, starting from 2014, exceeded the Soviet record in 1987 when 72.8 million $\mathrm{m}^{2}$ of residential real estate 
was put into operation. Significant growth in housing construction in many regions is ensured by the development of large-panel housing construction, but the difference in the rate of construction of residential buildings among Russian regions is very high. In 12 regions, a little more than half of the total area of residential buildings in Russia was built, and the remaining half is in 73 subjects, where construction volumes are lower [16].

The condition of the integrated home-building enterprises is of paramount importance for the development of large-panel housing construction. S. Nikolaev has noted that for 19852015 years, out of 400 home-building enterprises in the country with a capacity of more than $50,000 \mathrm{~m}^{2}$ per year, half of these enterprises and $80 \%$ in terms of their output have been lost [17].

Tomsk Oblast is a region that actively implements programs for the construction of housing and social facilities. During 2010 - 2015, in the region there was a steady growth in residential construction. In 2015, 699.1 thousand square meters were put into operation, which is $27.3 \%$ more than planned, an increase is of $112.92 \%$, which is above the average for Russia and the Siberian Federal District. It is noteworthy that $40.2 \%$ of housing is an individual construction. In general, housing increased from $21.4 \mathrm{~m}^{2}$ per person in 2010 to $23.4 \mathrm{~m}^{2}$ per person in 2015 , which is higher than the SFO level $\left(23 \mathrm{~m}^{2}\right)$ and $1 \mathrm{~m}^{2}$ behind the average for Russia $\left(24.4 \mathrm{~m}^{2}\right)$.

The commissioning of residential buildings per 1000 population increased from $418.5 \mathrm{~m}^{2}$ in 2010 to a record $649.6 \mathrm{~m}^{2}$ in 2015 [18]. In 2016, due to the crisis in the industry, the commissioning of residential buildings fell by $32.7 \%$ and was $435.8 \mathrm{~m}^{2}$ per 1000 people. At the same time, the volume of construction work increased by $10.7 \%$ compared to 2015 . The growth of construction and installation works was provided mainly due to the construction of social facilities and facilities of the oil and gas complex. A significant increase in the housing construction activity is ensured by the successful implementation of housing programs - "Housing for the Russian family", "Social mortgage", "Resettlement of citizens from the dilapidated and emergency housing."

The most successful in the region is the implementation of social facilities, primarily schools and facilities in the sphere of pre-school education. From 2013 to 201515 preschool institutions (kindergartens) were constructed on the territory of nine municipalities. To implement the social and infrastructure project, a form of public-private partnership (PPP) was used. Currently, all objects are put into operation, the cost of the project was 2.9 billion rubles, the total number of places for preschool children is 2840. At present, the PPP mechanism is actively used for the construction of schools, in 2016, construction units for 1160 pupils was put in commission, which significantly improves the social situation, especially in new residential areas.

The leading developer of the region and an active participant in PPP projects is the largest construction holding PC (Public Corporation) "Tomsk House Building Company" (THBC). Totally in 2015 there were 2,200 construction organizations on the territory of the Tomsk region, of which 27 are large and medium-sized, and 158 organizations are in the production of building materials. In 2014-2015 PC "THBC" provided more than 50\% of housing construction in the Tomsk region. $\mathrm{PC}$ "THBC" is a socially responsible construction holding uniting 23 enterprises, employing more than 4,500 employees. The production activity of the holding's enterprises covers the entire production cycle of building construction products from mining and processing of inert materials, production of reinforced concrete and construction materials to construction of facilities, provision of modern telecommunications and maintenance of housing stock.

The company has its own division Stroytekhinnovatsii THBC, which focuses on the applying of innovations in construction practice, participates in the implementation of housing programs, builds up to $70 \%$ of housing by mortgage programs. 


\section{Results and discussion}

The analysis of investment and construction activities has shown that the main priorities of town development in urbanized areas are:

1. Spatial development and architectural look of cities. So, in the Tomsk region, the construction of modern residential areas on the left bank of the Tom River is being carried out. The group of companies "Carieroupravlenie", functioning as an investor and developer is building a residential microdistrict "The North Park"; it is planned to build not only housing with "turnkey" finishing, but also to create its own engineering infrastructure. Since 2012, another large-scale project is being implemented - the "Tomsk Naberezhnye" 11 kilometers of length, which will make significant changes to the look of the town and its infrastructure.

Town-planning activity is carried out so that preserve historical building, objects of a cultural heritage, an accomplishment of natural reservoirs and embankments, modernization of gardening.

2. Construction of modern and comfortable residential areas on new, as well as on uncomfortable and unpromising territories. For 5 years, the project for the construction of the megadistrict "South Gate" has been designed, the "Solnechnaya Dolina" district is being built up, which includes several microdistricts, whose name was chosen by the population and corresponds to the "green" construction trend ("Sunflowers", "Green Hills", "Zarechie", etc.). A distinctive feature of new residential areas is the complex nature of the development and a new quality of the urban environment, based on the advantages of the natural landscape. The comfort of the conditions is ensured both by the internal planning and constructive solutions, and by the comfort of the yard spaces and adjacent territories, recreational zones, playgrounds and sports grounds, a network of footpaths, rollerdrome, roads, smart security systems, etc. are created. There are sufficient underground garages, ground parking in new areas.

Spatial development is carried out not only through the development of new territories, but also through the renovation of industrial areas. So, the "Radonezhsky" microdistrict is located on the territory of the former sleeper-impregnation plant, it goes to the embankment of Tom, next to it there is a picturesque lake - Ust-Kherepet. Preliminary, a land reclamation project was implemented.

Housing construction is not limited to the construction of high-rise buildings. In ecologically favorable areas of the city, townhouses are being built, corresponding in quality to the European type: individual entrance, garage, land, terrace.

3. Development of industrial housing construction based on the development and application of new technological and constructive solutions. Achievements and problems of developing large-panel housing construction in Russia are discussed annually at the International Scientific and Practical Conference "Development of large-panel housing construction in Russia" (InterConPan-2016). In the nearest future, the influence of largepanel housing construction on the urban environment and the level of housing provision will be crucial. To solve the problem of providing an aggregate floor space for citizens of Russia in the amount of $28-35 \mathrm{~m}^{2}$ per person, it is necessary to modernize the existing industrial housing construction base on an innovative basis.

The modern large-panel housing construction systems provide architectural maneuverability, the possibility of varying the length, orientation according to the conditions of insolation, configuration and flooring, the technology of building facades, the use of the first floors of buildings to accommodate publicly significant facilities, underground space. The comfort of an inhabited environment is determined not only by the external factors, but also by the planning decisions of living quarters. One of the indisputable advantages of efficiency is the possibility of flexible planning solutions that allow to create a different set 
of apartments, to carry out apartment redevelopment when the socio-economic situation changes. The "inner side" determines the comfort and convenience of apartments and fully depends on the structural design of the building, on the versatility and flexibility of the architectural and construction system $[18,19]$.

Thus, PC "THBC" specialists together with scientists developed a new house-building system "KUPASS" - a frame, universal, full-assembled architectural and construction system. The use of this system has made it possible to solve the problem of building energyresource-saving housing of an economic class. Kupass is an earthquake-proof house-building system with the A ++ energy saving class, provides a reduction in the material consumption from 10 to $15 \%$, energy consumption - up to $49 \%$. PC "THBC" uses the unique technology of frame house-building "CASCADE" for the construction of comfort-class housing. The system allows to realize interesting architectural and planning solutions, change the architectural look of the city, build houses with a greater number of storeys. Many-storeyed building of modern microdistricts differs by the variety of a number of storeys, walls material, constructive decision.

Currently, the region is actively developing prefabricated wooden frame-panel housing construction. The share of wooden buildings is planned to increase to $25 \%$. In addition to solving the problems of energy efficiency and environmental friendliness, wooden house construction solves another very important task - providing affordability to the consumer.

4. The priority factor determining the current development of the construction business trajectory is the orientation towards the use of energy-efficient and resource-saving technologies, "green" standards [20,21]. The tasks of increasing the objects energy efficiency are solved by modernizing the existing production of building structures and products, applying the above-mentioned house-building systems, and new energy-saving solutions, uses of renewable energy sources $[22,23]$. In fact, we are talking about the construction of a new type of buildings - eco-house real estate facilities $[24,25]$. In Tomsk, a unique project for the construction of a kindergarten (energy efficiency class "A") was implemented, the needs of which in heat resources are $100 \%$ provided through the use of geothermal energy.

5. Implementation of social projects, including those built on the development of cooperation between government and construction business. Tomsk region is one of the leaders in the development of PPP in the investment and construction sector. In 2016, the Tomsk region began to develop a project to create new student places in schools. By 2025 , it is planned to increase pupils in schools by $30 \%$ and the problem of building additional schools is very relevant. It is planned to use the PPP mechanism in the implementation of the project for the construction of medical institutions [26].

The construction complex enterprises actively participate in the implementation of environmental protection measures. It is the cleaning of rivers and lakes, modernization of gardening. In addition, enterprises are developing a new type of activity - improving commissioning facilities, producing flowerpots, flowerbeds, benches, etc. based on the innovative $3 \mathrm{D}$ technologies.

Thus, the analysis of town development in urbanized areas showed that the current priorities the construction companies are guided by in their architectural and design solutions, is the spatial development and comfortable arrangement of the human life environment. The social and environmental criteria for urban development, which provide a material basis for the development of the region's economy, are the priority areas of territories development. The imperative of social and environmental responsibility of the construction business interacting with the authorities when implementing socially significant investment projects, has become an integral factor in the development of the investment and construction sector in the region. 


\section{Conclusions}

The revealed tendencies in the development of town-planning activity have confirmed the focus on ensuring the safety and comfort of the urban environment, which is consistent with the principles of territories sustainable development. Implementation of socially-oriented projects depends on many factors including the development of social and environmental responsibility of business, which is based not only on compliance with laws, mandatory environmental requirements and standards, as well as on the initiative activities of economic entities. The subjects of construction activity initiate the adoption of additional, increased social and environmental requirements that construction projects must meet.

Formation and development of social and environmental responsibility as an initiative activity of the subjects of the construction business depends on the capabilities of the existing institutional environment. Undoubtedly certain prerequisites have already been formed, but for the further successful solution of the sustainable development of urbanized territories, it is necessary to institutionalize the social and environmental responsibility of the construction business as a system, which implies:

1. definition of goals and tasks for system development based on the peculiarities of urban spaces;

2. definition of functions in the context of sustainable development of territories;

3. definition of qualitative and quantitative system indicators of social and environmental responsibility of the construction business state;

4. improving interaction forms among participants in town development, including government, business and public organizations;

5. improving methods and tools for regulating town development: regulatory and legislative, technical, estimate, financial and credit, tax;

6. creating a new system for monitoring the social and environmental responsibility of the construction business state.

In the opinion of the authors, the institutionalization of social and environmental responsibility of the construction business is a mechanism for the environmentally oriented regulation of town development, the basic methodological principles of which are:

- compliance of instruments, methods of the institutional environment for the regulation of town-planning activities with a needs of socially and environmentally oriented model for the development of territories;

- providing environmental support for construction activities taking into account the full life cycle of construction products;

- observing social and environmental priorities for the development of the territory;

- integrated assessment of the consequences of investment projects for the creation of construction projects for human life environment;

- coherence of interests of the government, business and society in the process of implementing socially significant investment projects.

Thus, the modern development paradigm in urbanized territories is a model of spatial development that provides a safe and comfortable arrangement of the human environment based on the potential for socially and environmentally oriented development of the construction business.

\section{Acknowledgement}

The article was prepared with a financial support of the Russian National Scientific and Research Foundation within the framework of the research project "Model management technologies implementation of social and environmental responsibility in the construction business", project No. 16-32-00005. 


\section{References}

1. B.A. Morgunov, A.M. Bagin, M.L. Kozeltsev, A.A. Terentiev, Ecologiya cheloveka 4, 3-11 (2017)

2. A.N. Tetior, Environmental engineering 2, 57-67 (2008)

3. L.V. Plotnikova, Environmental management of urban environment quality in highly urbanized areas (Ecology of a megacity, 2008)

4. L.Y. Volskaya, V.V. Korolev, Vestnik of Tomsk State University of Architecture and Building 2(39), 24 - 33 (2013)

5. V. Il'ichev, V. Kolchunov, A. Emelyanov, N. Bakaeva, Applied Mechanics and Materials 725-726, 1224-1230 (2015)

6. P.G. Grabovyy, Real estate: economics, management 4, 12-19 (2016)

7. V.V. Buzyrev, I.P. Nuzhina, European Science and Technology I, 372 - 378 (2012)

8. V.V. Buzyrev, I.P. Nuzhina, Facilities and Enterprises PP, 43-50 (2013)

9. V.I. Telichenko, A.A. Benuzh, Architecture and Building 1, 118-121 (2016)

10. I.P. Nuzhina, O.B. Yudakhina, E.I. Kotik, E.G. Matyugina, International Conference on Economics and Management (ICEM 2015), 414-417 (2015)

11. I.G. Lukmanova, Industrial and civil construction 4, 29-33 (2014)

12. T. Meshcheryakova, Economy and entrepreneurship 1(54), 617-620 (2015)

13. A. Mottaeva, E. Chibisova, Bulletin of the Moscow state regional university. Series: Economy 1, 70-77 (2017)

14. E. Vasilyeva, Economy and entrepreneurship 6(83), 607-610 (2017)

15. A. Boykov, An. Моттаева, Economy and entrepreneurship 11-2(52-2), 174-178 (2014)

16. V.V. Buzyrev, A.Yu. Plakhtiy, Problems of the modern economy 1, 128-130 (2016)

17. S.V. Nikolaev, Housing construction 5, 1-5 (2015)

18. An. Mottayeva, Online magazine of science 6(19), 69 (2013)

19. S.V. Nikolaev, Housing construction 3, 15-23 (2016)

20. E.A. Zharova, N.N. Minaev, K.E. Filushina, A.M. Gusakov, N.V. Gusakova, Mediterranean Journal of Sciences 6(3), 155-160 (2015)

21. V.V. Elistratov, I.G. Kudryasheva, Journal of Engineering and Applied Sciences 5, 3509-3512 (2016)

22. A.M. Krygina, Housing construction 6, 57 -59 (2015)

23. Ch. He, Modernization science: The principles and methods of national advancement $\mathbf{1}$, 472-476 (2012)

24. L.N. Rudneva, I.G. Pchelintseva, M.A. Guryeva, International Journal of Economics and Financial Issues 6, 227-232 (2016)

25. E.N. Zakharova, A.A. Kerashev, V.V. Prokhorova, G.V. Gorelova, A.A. Mokrushin, Mediterranean Journal of Social Sciences 6, 295-302 (2015)

26. T.V. Kasianenko, Y.I. Nagornyi, Actual Problems of Economics 5, 313-320 (2015) 